\title{
Proposed Mechanisms for the Fragmentation of Doubly Allylic Alkenamides (Tingle Compounds) by Low Energy Collisional Activation in a Triple Quadrupole Mass Spectrometer
}

\author{
Richard D. Hiserodt, Barry M. Pope, Michael Cossette, \\ and Mark L. Dewis \\ Research and Development, International Flavors and Fragrances Inc. (IFF), Union Beach, New Jersey, USA
}

\begin{abstract}
Tingle compounds are a class of alkenamides with organoleptic properties that include a numbing or a pins and needles effect that is generally perceived on the lips and in the mouth when consumed. They occur in nature in a number of botanical species. Spilanthol and Pellitorine are important examples of tingle compounds. A number of homologs and analogs were synthesized to study the effect of chain length, double bond location, and amide moiety on the tingle effect. This also provided the opportunity to study the behavior of these compounds in the collision cell of a triple quadrupole mass spectrometer. The doubly allylic 2E,6Z-alkenamides, which made up the largest class studied, fragmented in a characteristic way to produce a distonic radical cation and a cyclopropene cation. Mechanisms for the formation of these ions are proposed. The mechanisms are supported by energy-resolved mass spectrometric data, the analysis of deuterated analogs and homologs that are not doubly allylic, and exact mass measurements. Exceptions to the proposed mechanisms are also presented. These data represent the first attempt to apply mechanistic principles to the product ions observed in the MS/MS spectra of these compounds. The authors believe the results of this study will facilitate the identification of these and similar compounds and contribute to the fundamental understanding of the behavior of alkenamides in the collision cell of a triple quadrupole mass spectrometer. (J Am Soc Mass Spectrom 2004, 15, 1462-1470) (c) 2004 American Society for Mass Spectrometry
\end{abstract}

$\mathrm{T}$ Tingle compounds are a subset of the alkenamide family of compounds and are described extensively in the phytochemistry literature [1, 2]. They demonstrate a sensorial effect generally perceived on the tongue, gums, teeth, cheeks, roof of the mouth, and lips when chewed or otherwise administered to the mouth at concentrations in the ppm range. Compounds possessing tingle character or tingling paresthesia are most commonly described as producing a numbing anesthetic or a pins and needles effect and are found in nature in a number of botanical species [3]. They are found in the genera Achilla (yarrow), Acmella (spotflower), Echinacea (purple cornflower), Heliopsis (heliopsis), and Spilanthes (spilanthes) of the family Asteraceae; Centium (toothache grass) of the family Poaceae; Piper

Published online September 18, 2004

Address reprint requests to Dr. R. D. Hiserodt, Research and Development, International Flavors and Fragrances Inc. (IFF), 1515 State Highway 36, Union Beach, NJ 07735, USA. E-mail: Richard.hiserodt@iff.com (pepper) of the family Piperaceae; and Zanthoxylum (prickly ash) of the family Rutaceae. Four that are of particular interest are Spilanthol (12) [4], which was isolated from Heliopsis for this work; Pellitorine (18) [5-7] which was synthesized; and Bungeanool and the sanshools $[1,2,8]$ which served as models for compounds synthesized.

Historically, the focus of plant research has been in the area of anti-microbial activity, therefore, more is known in the scientific literature about the antifungal, anti-bacterial, and insecticidal activity of these compounds than about their organoleptic properties. The authors synthesized a range of alkenamides (1-19, excluding 12 which was isolated from Heliopsis). There were two goals associated with this work. One was to compare the oral activity and taste effects of 1-19 with the known tingle compounds discussed above. The second objective was to study the fragmentation characteristics of a class of compounds with small variations in structure, under low 
collisional activation in a triple quadrupole mass spectrometer, and how these differences effect their product ion spectra.

There are two liquid chromatography-mass spectrometry (LC/MS) methods reported in the literature for the quantitative and qualitative determination of alkamides, including alkenamides that are doubly allylic, in natural product extracts utilizing single quadrupole mass spectrometers. Identifications of unknowns were either tentative, based on molecular weight or predicted elution order; or by off-line methods after preparative LC $[9,10]$. The data presented in this paper represent the first attempt to apply mechanistic principles to the product ions observed in the MS/MS spectra of these compounds. The authors believe this will facilitate the identification of these and similar unknown compounds.

\section{Experimental}

Synthesis

$4 Z$-aldehydes were used to synthesize the $2 E, 6 Z$-acids for 1-9, 11, 14-17 by reaction with malonic acid using pyridine as a catalyst. Subsequent reaction of the unsaturated acids with ethyl chloroformate in the presence of triethylamine followed by reaction with the relevant amine or deuterated analog yielded the desired 2E,6Zalkenamide.

Undeca-2E,4E,8Z-trienoic acid isobutyl amide (13) and undeca-2E,4E,8Z-trienoic acid dimethyl amide (10) were prepared from undeca-2E,4E,8Z-trienoic acid. Structures 18 and 19 were prepared by silver oxide oxidation of their respective aldehydes followed by reaction with isobutyl amine to form the desired $2 E, 4 E$ alkenamide. Deca-2E,6Z,8E-trienoic acid isobutyl amide (Spilanthol 12) was isolated by liquid-liquid extraction from Heliopsis.

All of the alkenamides were purified by distillation or recrystallization. They were $\geq 95 \%$ pure by gas chromatography and their structures were confirmed by NMR.

\section{Mass Spectrometry}

A TSQ 7000 triple quadrupole mass spectrometer, with an API2 source, was interfaced to a SpectraSystem P4000 gradient pump (Thermo Electron Corporation, San Jose, CA) for this work. Samples were diluted in methanol and infused into the mobile phase stream, at $10 \mu \mathrm{L} / \mathrm{min}$, using a Harvard Model 11 syringe pump (Harvard Apparatus, Inc., Holliston, MA). The mobile phase, which consisted of $80 \%$ acetonitrile (1\% HOAc) and $20 \% \mathrm{H}_{2} \mathrm{O}(1 \% \mathrm{HOAc})$ and is the approximate composition for elution of these compounds from a $15 \mathrm{~cm} \mathrm{C-18} \mathrm{column,} \mathrm{was} \mathrm{pumped}$ at a flow rate of $0.2 \mathrm{~mL} / \mathrm{min}$. The mass spectrometer was operated in the positive ion mode using atmo- spheric pressure chemical ionization (APCI). The vaporizer and heated capillary temperatures were $450{ }^{\circ} \mathrm{C}$ and $250{ }^{\circ} \mathrm{C}$ respectively. The corona discharge was set to $5 \mu \mathrm{A}(4.1 \mathrm{kV})$. The sheath gas was set to 70 psi and the auxiliary gas to 20 units. The electron multiplier was optimized for a gain of 300,000 (1290 V).

Product ion spectra were obtained by using Q1 to focus selected precursor ions $(\mathrm{M}+\mathrm{H})^{+}$into the collision cell (Q2) which was maintained at $2 \mathrm{mT}$ with argon (Ar). The offset voltage for Q2 was varied from -22 to $-27 \mathrm{~V}$ depending on the molecular weight of the compound analyzed and Q3 was scanned from $m / z 25-275$ in $1 \mathrm{~s}$. Resolutions for Q1 and Q3 were maintained at 0.7 FWHM, and were tuned and calibrated with caffeine/MRFA/Ultramark 1621.

Accurate mass measurements were made using a TSQ Quantum AM triple quadrupole mass spectrometer (Thermo Electron Corporation, San Jose, CA). Precursor ions $(\mathrm{M}+\mathrm{H})^{+}$were generated in the positive ion mode using electrospray ionization (ESI). The spray voltage was $5.0 \mathrm{kV}$ and the sheath and auxiliary gasses were 70 and 10 units, respectively. Product ions were generated in the collision cell (Q2) which was maintained at $2 \mathrm{mT}$ with Ar. The offset voltage was $-25 \mathrm{~V}$. Q1 resolution was set to $0.1 \mathrm{FWHM}$ to reduce the possibility of interferences from unresolved peaks. Tryptophan product ions at $\mathrm{m} / \mathrm{z} 91.0542$ and 143.0730 were used as external lock (reference) masses. Loop injections were made into a mobile phase stream consisting of $\mathrm{H}_{2} \mathrm{O} / \mathrm{CH}_{3} \mathrm{OH}(50: 50)$ at a flow rate of 0.2 $\mathrm{mL} / \mathrm{min}$.

Energy-resolved mass spectrometric (ERMS) data was acquired while infusing methanolic solutions of selected alkenamides using the conditions described above for acquiring single energy product ion spectra. An eighteen segment scan sequence was set up where the collision cell offset voltage was incremented from 7-40 V in $3 \mathrm{~V}$ steps and then 40-70 V in $5 \mathrm{~V}$ steps. Each segment was scanned from $\mathrm{m} / \mathrm{z} 25-275$ in $1 \mathrm{~s}$ for a $30 \mathrm{~s}$ duration. Spectra were averaged over each segment and used to generate breakdown curves for selected ions.

\section{Results and Discussion}

2E,6Z-Unsaturated amides (1-9, 11 and 14) fragment under low energy collisional activation in a characteristic way that is structurally diagnostic for amides with a double bond configuration that is doubly allylic. The two characteristic ions are thought to be formed by charge-remote homolytic cleavage to yield a resonance stabilized distonic radical cation and by a chargeinduced mechanism that proceeds through a bicyclic intermediate to yield a resonance stabilized cyclopropene cation. These fragmentation mechanisms also apply to undeca-2E,4E,8Z-trienoic acid dimethyl amide (10), deca-2E,6Z,8E-trienoic acid isobutyl amide (12, Spilanthol) and undeca-2E,4E,8Z-trienoic acid isobutyl 
Table 1. $m / z$ values and per cent relative intensity (RI) for the distonic radical cation, cyclopropene or cyclopentadiene cationic species, and precursor ions $(\mathrm{M}+\mathrm{H})^{+}$in $\mathbf{1 - 1 4}$

\begin{tabular}{cccc}
\hline Cpd. no. & $\begin{array}{c}\text { Distonic radical } \\
\text { cation } m / z \\
(\% \mathrm{RI})\end{array}$ & $\begin{array}{c}\text { Cyclopropene or } \\
\text { cyclopentadiene } \\
\text { cationic species } \\
m / z(\% \mathrm{RI})\end{array}$ & $\begin{array}{c}\text { Precursor ion } \\
\mathrm{M}+\mathrm{H}^{+} \\
(\% \mathrm{RI})\end{array}$ \\
\hline \hline 1 & $99(100)$ & $84(64)$ & $168(20)$ \\
2 & $113(55)$ & $98(100)$ & $182(8)$ \\
3 & $113(50)$ & $98(100)$ & $224(17)$ \\
4 & $141(32)$ & $126(60)$ & $210(15)$ \\
5 & $141(38)$ & $126(100)$ & $252(34)$ \\
6 & $118(100)$ & $102(99)$ & $187(28)$ \\
7 & $155(18)$ & $140(23)$ & $224(28)$ \\
8 & $113(48)$ & $98(100)$ & $182(11)$ \\
9 & $119(73)$ & $103(100)$ & $188(16)$ \\
10 & $139(100)$ & $124(34)$ & $208(20)$ \\
11 & $127(11)$ & $112(53)$ & $196(10)$ \\
12 & $141(32)$ & $126(90)$ & $222(3)$ \\
13 & $167(100)$ & $152(65)$ & $236(26)$ \\
14 & $125(100)$ & $110(6)$ & $194(11)$ \\
\hline
\end{tabular}

amide (13) and depend on the functionality attached to the nitrogen. Structures $\mathbf{1 0}$ and $\mathbf{1 3}$, which have two double bonds in conjugation with the carbonyl group, would proceed through a bicyclic intermediate to form a cyclopentadiene cationic species according to the mechanism proposed here. Table 1 contains a list of $\mathrm{m} / \mathrm{z}$ values and relative intensities (RI) for these ions and the precursor ions $(\mathrm{M}+\mathrm{H})^{+}$for $\mathbf{1 - 1 4}$.

\section{Charge-Remote Mechanism}

Charge-remote fragmentations occur when the charge is remote from the fragmentation site and the fragmentation is uninfluenced by it. They are often observed under high energy collisional activation in tandem magnetic sector mass spectrometers. Pericyclic 1,4-conjugate elimination, homolytic cleavage, and other gasphase thermolytic processes have been used to model charge-remote fragmentations [11-17].

Denekamp et al. studied fragmentation mechanisms for 1-phenyl-4-pyridyl-3-butene and substituted homologs and analogs [18]. These are doubly allylic quaternary ammonium ions where the fragmentation site is also associated by conjugation with the positive charge. In spite of this, the authors state the fragmentation is not necessarily charge-induced. These researchers describe three fragmentation routes for these compounds with the dominant one depending on whether the substituent is electron releasing or withdrawing. Two routes involve heterolytic cleavages producing cationic species and neutral amines or substituted styrenes and the third involves homolytic cleavage producing a distonic radical cation plus a neutral radical. This third route best explains the formation of the distonic radical cations in 1-14 because of the lower bond dissociation energy for breaking a doubly allylic carbon-carbon bond and the stability of the radical cation and neutral radical products. This mechanism is depicted in Scheme $\mathbf{1}$ for $\mathbf{2}$ and the product ion spectra is shown in Figure 1.

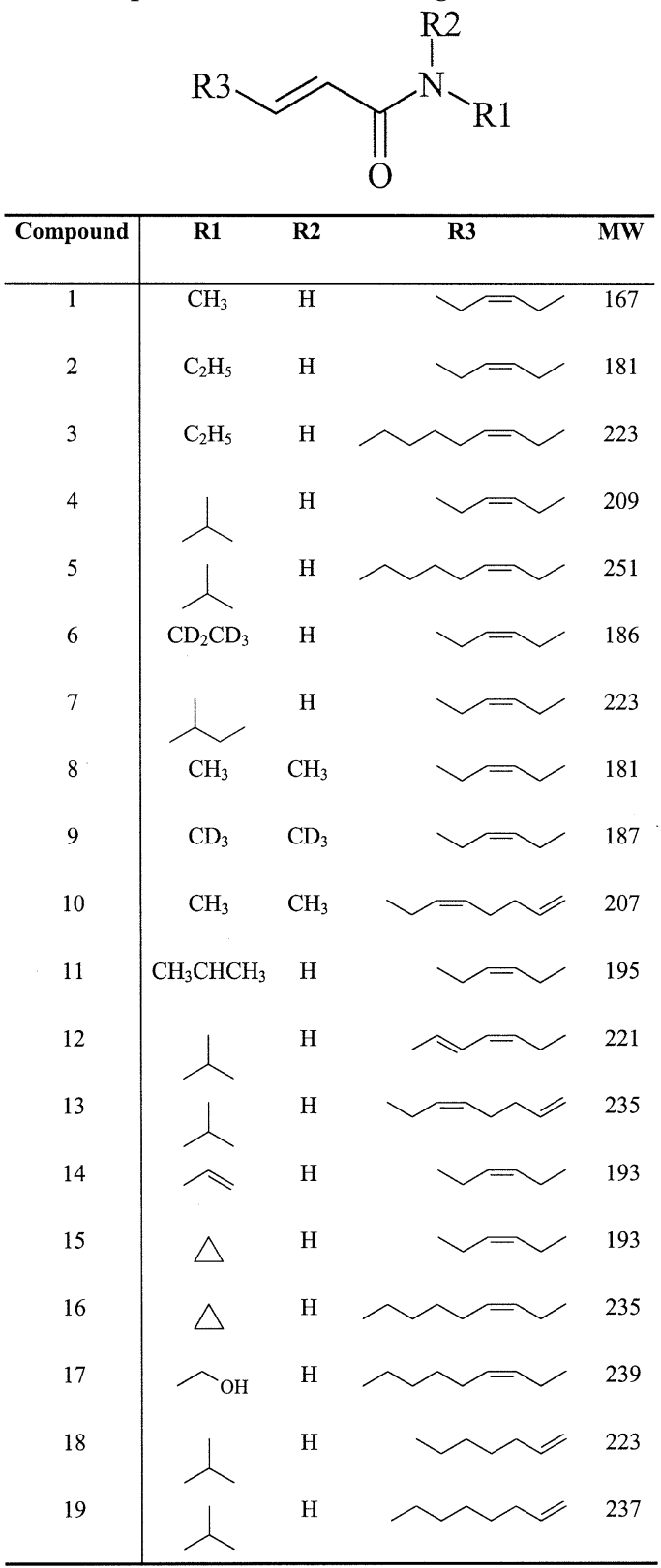

There are also analogies in a study by Contado et al. to possible mechanisms for charge-remote fragmentation of unsaturated fatty acids [19]. They describe a two step mechanism for the observed fragmentation of lithiated cis-7-dodecenoic acid that involves initial formation of a radical cation by homolytic cleavage of an allyl carboncarbon bond distal to the charge site. Through resonance, the double bond moves to the terminal position of the radical cation and a hydrogen atom is lost in step two forming a diene cationic species. The radical cation formed in the fragmentation of 1-14 is highly resonance stabilized; there is less of an energy advantage to losing a hydrogen atom and its formation competes effectively with heterolytic loss of other cations through chargeinduced mechanisms. 


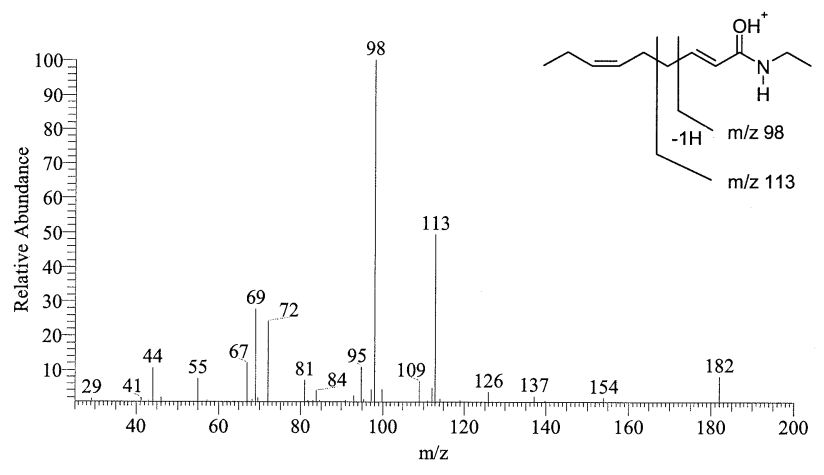

Figure 1. Product ion spectrum of 2.

Scheme $\mathbf{1}$ also indicates the distonic radical cation undergoes a hydrogen rearrangement and fragmentation to form an acyllium ion at $m / z 69$ with subsequent loss of carbon monoxide $(\mathrm{CO})$ to form the propene cation at $m / z 41$. This is supported by energy-resolved mass spectrometric (ERMS) data.

The spectrometric information in a MS/MS spectrum acquired at a single collision energy is limited and can be significantly enhanced by acquiring spectra at increasingly greater collision cell energies (ERMS). In the low energy collision cell of a triple quadrupole mass spectrometer, this results in an increase in the internal energy of the precursor ion which leads to further dissociation. A plot of collision energy versus relative intensity of selected fragment ions leads to the generation of breakdown curves [20]. Evaluation of these breakdown curves can provide information on fragmentation mechanisms such as distinguishing between competitive and consecutive fragmentation pathways, the stability of product ions, and identification of first and subsequent generation product ions [21-26]; identification of isomers and tautomers [27-29]; and development of library searchable MS/MS spectra [30, 31]. Since the internal energy of the precursor ion is not rigorously known, breakdown curves provide a qualitative picture of a fragmentation mechanism.

The breakdown curves for the distonic radical cation $(m / z 113)$, acyllium ion $(m / z 69)$, and propene cation $(m / z$

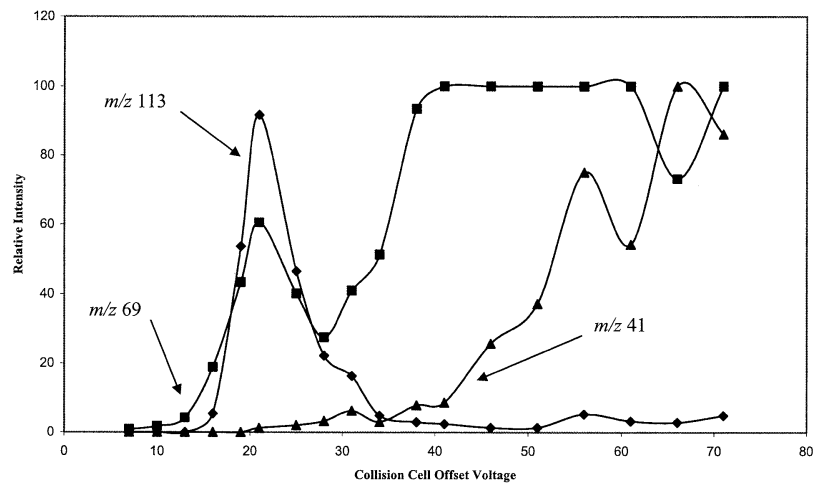

Figure 2. Breakdown curves for the distonic radical cation $(\mathrm{m} / \mathrm{z}$ 113), acyllium ion $(m / z 69)$, and propene cation $(m / z 41)$ for 2.
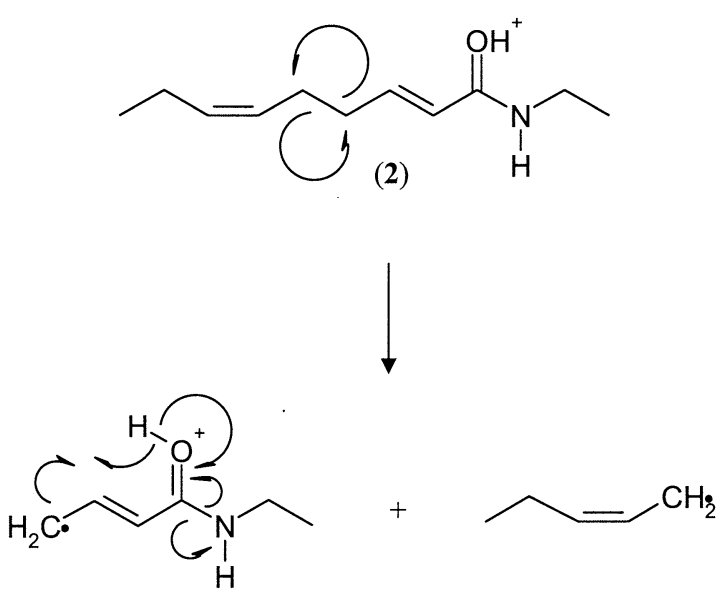
distonic radical cation
$\mathrm{m} / \mathrm{z} 113$

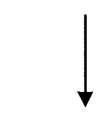<smiles>C/C=C/C#[O+]</smiles><smiles>C=C[CH+]C</smiles>

$m / z 41$

Scheme 1. Proposed mechanism for the formation of the resonance stabilized distonic radical cation in the product ion spectrum of $\mathbf{2}$ and subsequent fragmentation.

41) for 2 are shown in Figure 2. The curve for $m / z 69$ shows two appearance energies; one at $13 \mathrm{~V}$ and one at $28 \mathrm{~V}$. The low energy appearance is due to the formation of the pentene cation which can be easily formed by inductive cleavage of the resonance form of the protonated amide with the positive charge on C3. The higher energy appearance is due to the acyllium ion at $m / z 69$. Because this occurs at a higher energy than the breakdown curve for the distonic radical cation at $m / z 113$, it is a good indication that the acyllium ion is a first generation product of this ion. Similarly, because the appearance energy for the propene cation at $m / z 41$ is at a higher energy than the acyllium ion $(40 \mathrm{~V}$ versus 28 $\mathrm{V})$, the propene cation is a first generation product of the acyllium ion and a second generation product of the distonic radical cation.

Wensing et al. reported a similar observation in their development of a fragmentation mechanism for diethyl alkyl phosphonates. Breakdown curves for the sequential loss of two ethylene molecules from the precursor ion for diethyl propyl phosphonate were shown to occur at increasingly higher energies. The conclusion 


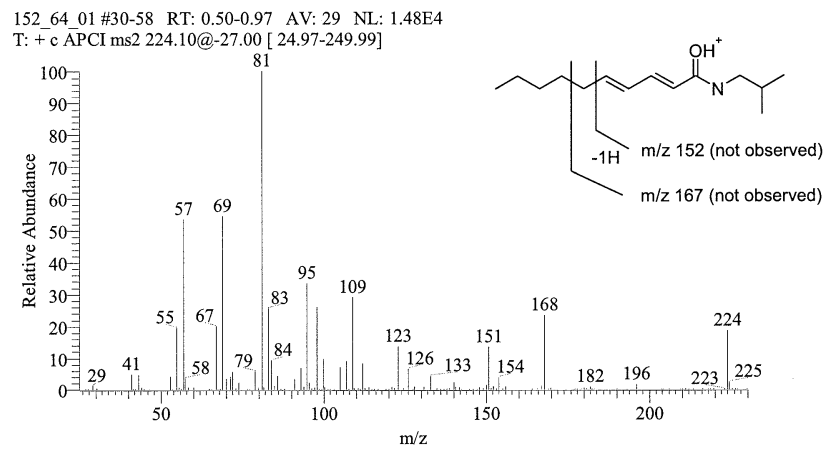

Figure 3. Product ion spectrum of Pellitorine (18).

was drawn that these were first and second generation product ions [24]. Similarly, Harrison, in his comparison of breakdown curves generated by in-source CID versus low energy CID in a triple quadrupole mass spectrometer, demonstrated that the sequential formation of product ions from peptide and alkylphenylammonium precursor ions occured at increasingly higher energies [21, 22].

Pellitorine (18) and 19 are not doubly allylic and are stable to the formation of distonic radical cations under low energy conditions. This ion is not observed in their product ion spectra (Figure 3). The cyclopropyl amides (15 and 16) are doubly allylic but do not undergo homolytic cleavage to form radical cations as depicted in Scheme 1. The reason for this lies in the preference to form the acyllium ion at $\mathrm{m} / \mathrm{z} 137$ from cleavage of the amide bond. This is supported by ERMS data and is discussed in more detail in the next section. Structure $\mathbf{1 7}$ is also doubly allylic and does not form a radical cation. Its product ion spectra is dominated by the homolytic loss of a hydroxyl radical at $\mathrm{m} / \mathrm{z} 223$ and formation of the acyllium ion at $\mathrm{m} / \mathrm{z} 179$ which is also supported by ERMS data (not reported).

\section{Charge-Induced Mechanism}

Charge-induced mechanisms are characterized by rearrangements such as double bond isomerization, cyclization, and hydrogen transfer and result in charge migra-

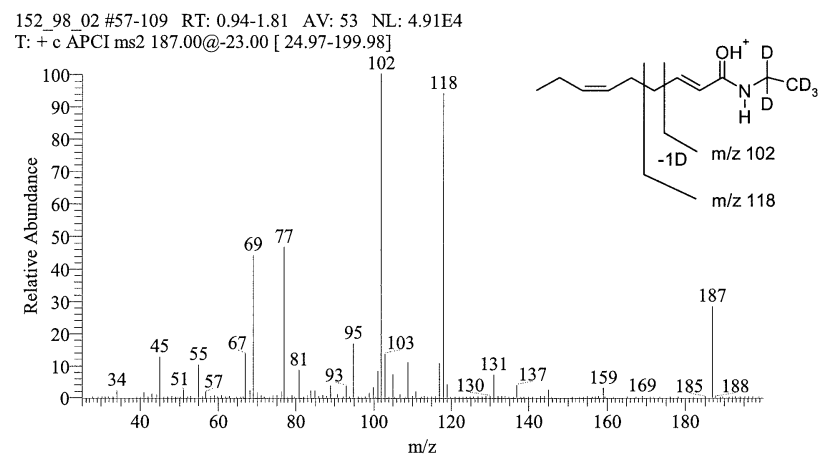

Figure 4. Product ion spectrum of 6 .
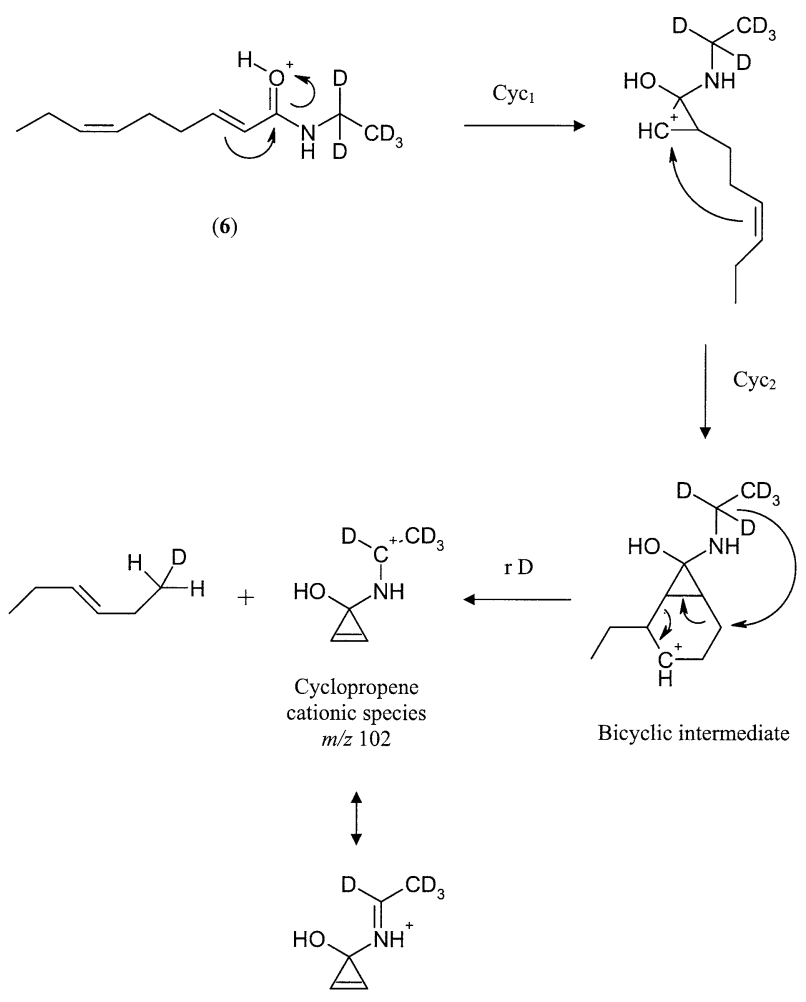

Scheme 2. Proposed mechanism for the formation of the resonance stabilized cyclopropene cationic species in the product ion spectrum of 6 .

tion so that the charge is integral to the observed cleavage site. This is generally considered to obscure the structural detail that results from charge-remote processes [12, 32-34]. The proposed mechanism for the formation of the cyclopropene cation in $2 E, 6 Z$-unsaturated amides $(\mathbf{1 - 9}, \mathbf{1 1}$ and $\mathbf{1 4})$ is postulated to be chargedinduced and involves initial formation of a bicyclic intermediate followed by hydrogen/deuterium transfer from the amide alkyl group and subsequent loss of an alkene to form a resonance stabilized product ion. This also applies to Spilanthol (12) which is a $2 E, 6 Z, 8 E$ unsaturated amide. Structures 10 and 13, which have two double bonds conjugated with the carbonyl, would proceed through a bicyclic intermediate to form a resonance stabilized cyclopentadiene cation. Analysis of the product ion spectra of the deuterated amides (6 and 9) clearly indicates the mechanism involves transfer of a hydrogen/deuterium from the amide alkyl group to the departing alkene since the cyclopropene cation for the deuterated analogs appears at $m / z 102$ and 103, for 6 and 9, respectively, rather than $\mathrm{m} / \mathrm{z} 103$ and 104 which would be the case if all five deuteriums remained associated with the alkyl group attached to the nitrogen. Scheme 2 shows the proposed mechanism for the fragmentation of 6 to yield the cyclopropene cation at $\mathrm{m} / \mathrm{z} 102$ and Figure 4 shows the product ion spectra for this compound. The deuterium abstracted was not specified by the analog synthesized for this experiment. It is depicted as in Scheme 2 because abstracting the 


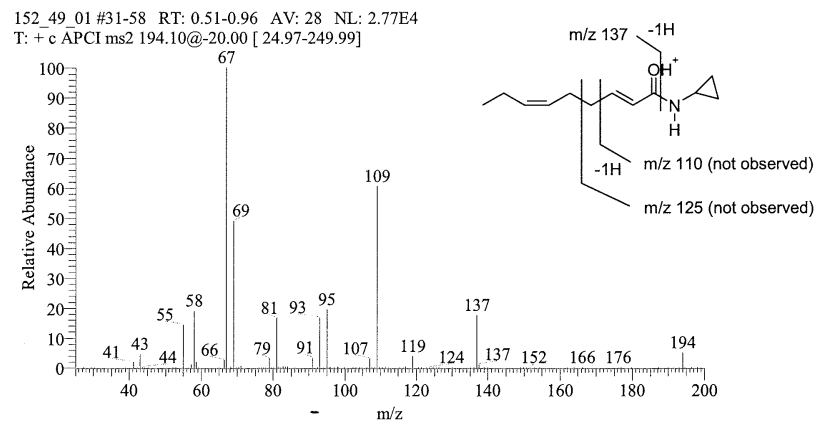

Figure 5. Product ion spectrum of $\mathbf{1 5 .}$

deuterium from the carbon alpha to the nitrogen leads to a resonance stabilized product ion through a sixmembered transition state. Additionally, the doubly allylic methyl amide (1) fragments to yield the expected cyclopropene cation.

The 1-propene amide (14) only formed a low intensity cyclopropene cation $(\mathrm{RI}=6 \%)$ possibly because a more favorable five-membered ring intermediate was formed with the propene functionality attached to the nitrogen atom. Cyclopropene cationic species were not observed in the product ion spectra of $2 E, 6 Z$-unsaturated amides 15-17. As mentioned in the previous section, this is due to the preferential formation of the acyllium ion at $m / z$ 137. Although it is not immediately apparent from the MS/MS spectra of $\mathbf{1 5}$ in Figure 5, Figure 6 shows that the appearance energy for the acyllium ion generated from 15 occurs at a lower energy $(<7 \mathrm{~V})$ than the acyllium ion for $2(13 \mathrm{~V})$; both at $\mathrm{m} / \mathrm{z}$ 137. It also occurs at a lower energy than formation of the cyclopropene cation at $m / z 98(15 \mathrm{~V})$ and the distonic radical cation at $m / z 113(13 \mathrm{~V})$ for 2 . Even though the intensity of the acyllium ion for 2 cannot be compared directly with the intensity for the acyllium ion for 15, it can be compared to the respective cyclopropene cation and the distonic radical cation. The breakdown curves indicate the acyllium ion is significantly less stable than these other two ions. Again, referring to the work by Wensing et al, the second generation product ion after two sequential losses of ethylene from diethyl alkyl phosphonates that was most intense was judged to be more stable [24].

Similar observations were made for the doubly allylic ethanol amide (17) which also did not form a cyclopropene cation or a distonic radical cation. ERMS data showed that the appearance energy for loss of a hydroxyl radical at $\mathrm{m} / \mathrm{z} 223$ was $<7 \mathrm{~V}$ and formation of the acyllium ion at $\mathrm{m} / \mathrm{z} 179$ was $13 \mathrm{~V}$ (data not included). Again, both were lower than or equal to the appearance energy for the cyclopropene cation and distonic radical cation for 2.

A mechanism taking advantage of a resonance form of the protonated amide with the positive charge on the nitrogen atom was initially considered. It involved formation of a bicyclic intermediate (20) followed by loss of a neutral alkene and formation of a product ion that was essentially a resonance stabilized $\beta$-lactam cation. There were two things wrong with this mechanism. The resonance form is not the most favored form and the charge was not always integral to the bond being broken. It was reasoned that production of a resonance stabilized product ion would drive the fragmentation. Analysis of the product ion spectra of the secondary amides (8-10) showed 20 to be an unlikely intermediate. The product ion spectra of these compounds showed the same fragmentation characteristics observed in the primary amides and yet the secondary amides could not form the equivalent bicyclic intermediate (21) unless a methyl group was transferred. The mass spectrometric data did not support this. The ions for the cyclopropene cation are shown in Figure 7 for the dimethyl amide (8) and its deuterated analog (9) at $\mathrm{m} / \mathrm{z} 98$ and 103 respectively. Since it is more satisfying to describe the behavior of similar molecules by a single mechanism, Scheme 2 was proposed for both observations. Additionally, breakdown curves for the formation of the cyclopropene cation at $\mathrm{m} / \mathrm{z} 98$ for $\mathbf{8}$ and 2 have similar shapes and appearance energies which indicates they are formed by the same mechanism (Figure 8).

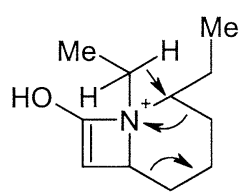

20

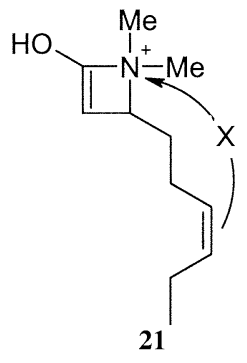

21
ERMS data does not support a consecutive pathway for the formation of the ion at $m / z 102$ for 6 (Scheme 2). For instance, a loss of ethylene is observed in the MS/MS spectrum of 6 at $\mathrm{m} / z 159$ (Figure 4). A subsequent loss of deuterated butene would lead to an ion at $m / z$ 102; the same mass as the cyclopropene cation. However, the appearance energy for loss of ethylene is the same as for formation of the ion at $m / z 102$ indicat-

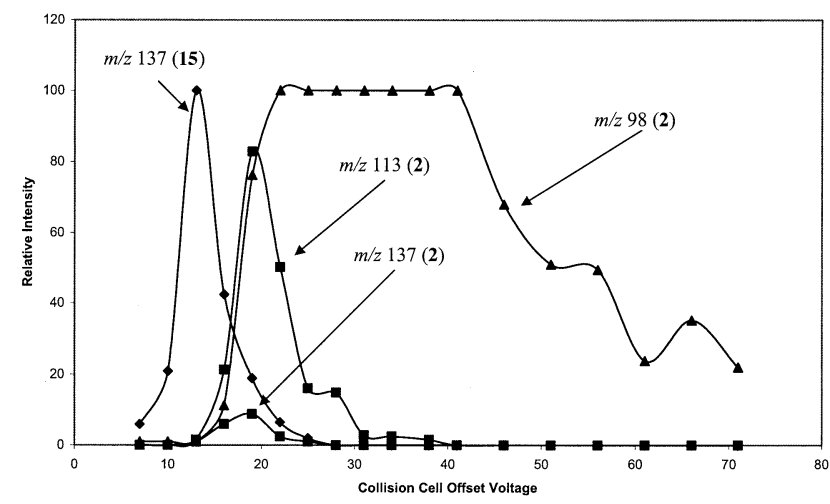

Figure 6. Breakdown curves for the acyllium ion $(m / z 137)$, distonic radical cation $(\mathrm{m} / \mathrm{z} 98)$, and cyclopropene cation $(\mathrm{m} / \mathrm{z} 98)$ for 2 and acyllium ion $(m / z$ 137) for 15. 

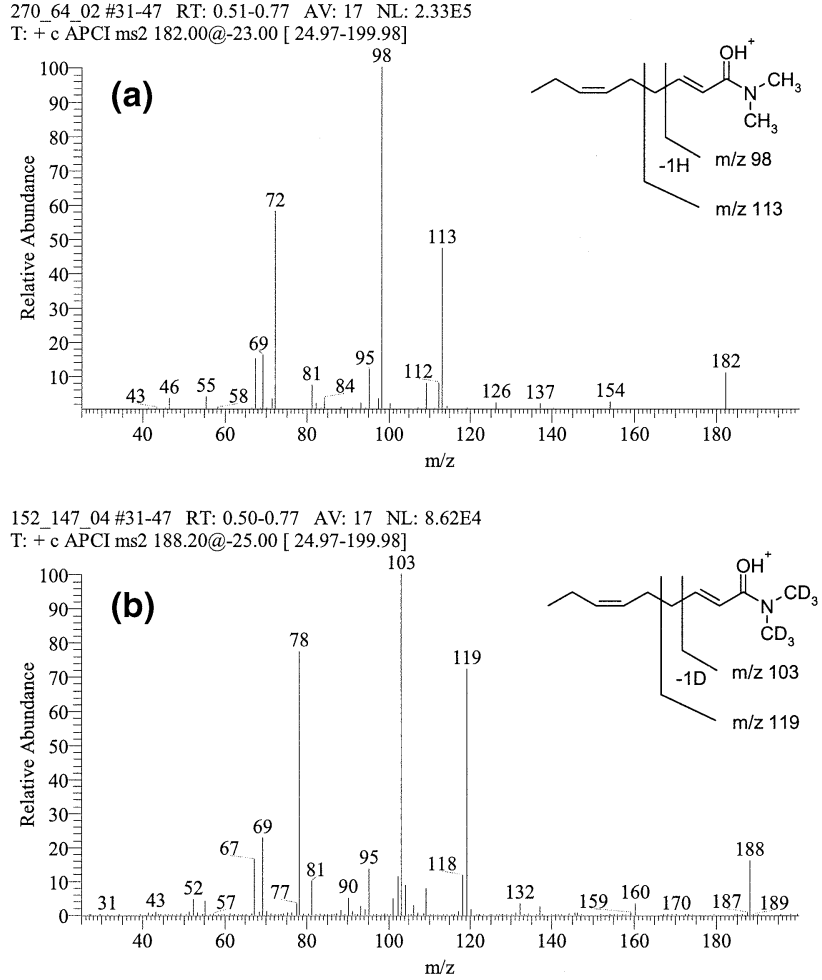

Figure 7. (a) Product ion spectrum of 8 and (b) product ion spectrum of 9 .

ing these are competitive events rather than consecutive as in the $m / z 113 \rightarrow 69 \rightarrow 41$ sequential losses from the distonic radical cation for 2 (Figure 9). Alternatively, the loss of deuterated butene is not observed from the protonated amide of $\mathbf{6}$ so a sequence involving this loss followed by loss of ethylene is not likely.

Additional support for the proposed mechanism in Scheme 2 is shown in the product ion spectra of Pellitorine (18), in Figure 3, and 19 which are not doubly allylic. These compounds, in addition to being stable to homolytic cleavage, cannot form the bicyclic intermediate that leads to formation of the cyclopentadiene

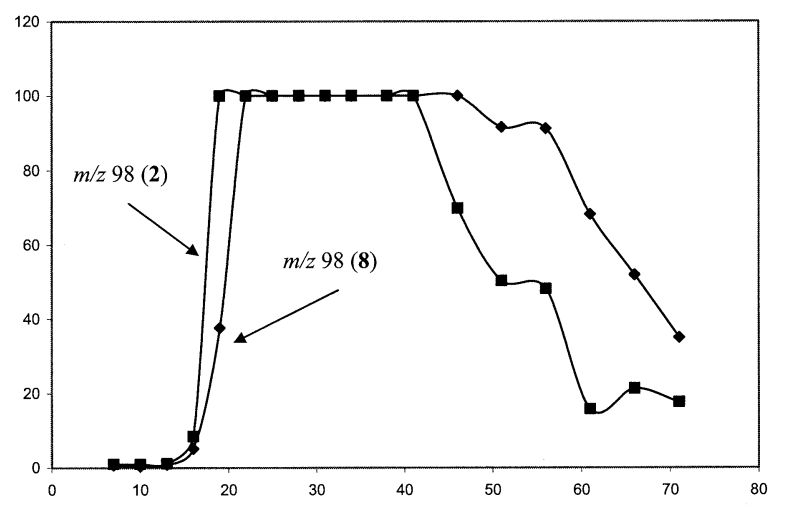

Figure 8. Breakdown curves for formation of the cyclopropene cation for the doubly allylic ethyl amide (2) and dimethyl amide (8).

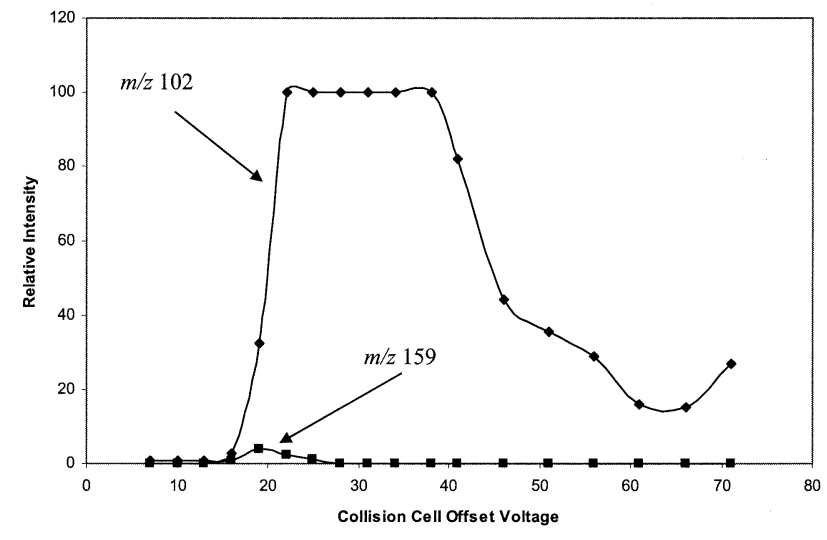

Figure 9. Breakdown curves showing the competitive formation of the cyclopropene cation $(\mathrm{m} / \mathrm{z} 102)$ and loss of ethylene $(\mathrm{m} / \mathrm{z} 159)$ from 6 .

cationic species at $\mathrm{m} / \mathrm{z} 152$ - the relevant cationic species for $2 E, 4 E$-unsaturated amides. This product ion is not observed in the spectra for these compounds. However, the observation of a low intensity product ion at $\mathrm{m} / \mathrm{z} 126$ in the spectra of Pellitorine (18) in Figure 3, and 19 suggest the formation of a cyclopropene cation that would proceed through a four membered ring bicyclic intermediate.

\section{Other Charge-Induced Fragmentations}

The high mass region for $\mathbf{1}-\mathbf{1 4}, \mathbf{1 8}$ and $\mathbf{1 9}$ was populated with low intensity ions from loss of neutral alkenes from the precursor ion. These were predominantly ethylene, propene, and butene. Analysis of the deuterated ethyl amide (6) shows these neutral losses to originate from the acid portion of the molecule and consequently does not give any indication of the alkyl moiety attached to nitrogen (compare Figures 1 and 4). Even though 4 and $\mathbf{1 1}$ show a distinct loss of 56 and 42 from the precursor ion, which could be diagnostic for isobutyl and isopropyl moieties attached to nitrogen, the methyl amide (1) also shows a distinctive loss of 56 . The neutral loss of alkenes from the precursor ion was not observed in 15-17.

Identification of the acyllium ion from cleavage of the amide bond, aided by the accompanying loss of $\mathrm{CO}$, will indirectly lead to the identification of the carbon number of the alkyl moiety attached to nitrogen. The acyllium ion formed by cleavage of the amide bond for 1-19 was detected at a relative intensity of $2-19 \%$ and the ion for the accompanying loss of $\mathrm{CO}$ was detected at a relative intensity of $2-61 \%$.

The secondary amides (8-10) formed intense acyllium ions (RI $=70-80 \%$ ) from cleavage opposite the amide bond. These acyllium ions were detected in the product ion spectra of the other compounds studied but were less intense (RI $=0-60 \%$ ) (Figure 6). 
Table 2. Determination of exact mass for the cyclopropene cationic species and distonic radical cation in 2 and 6

\begin{tabular}{|c|c|c|c|c|}
\hline & \multicolumn{2}{|c|}{ Structure 2} & \multicolumn{2}{|c|}{ Structure 6} \\
\hline & $\begin{array}{c}\text { Cyclopropene } \\
\text { cation }\end{array}$ & Radical cation & $\begin{array}{c}\text { Cyclopropene } \\
\text { cation }\end{array}$ & Radical cation \\
\hline Mass \#1 (u) & 98.0601 & 113.0838 & 102.0840 & 118.1142 \\
\hline Mass \#2 (u) & 98.0605 & 113.0845 & 102.0854 & 118.1136 \\
\hline Mass \#3 (u) & 98.0598 & 113.0822 & 102.0862 & 118.1153 \\
\hline Avg. mass (u) & 98.0601 & 113.0835 & 102.0852 & 118.1144 \\
\hline Rel. Std. Dev. & 0.03512 & 0.11511 & 0.11136 & 0.08651 \\
\hline Calc. Mass $(u)^{a}$ & 98.0600 & 113.0835 & 102.0852 & 118.1149 \\
\hline$\Delta$ Mass $(\mathrm{u})$ & 0.0001 & 0.0000 & 0.0000 & 0.0005 \\
\hline
\end{tabular}

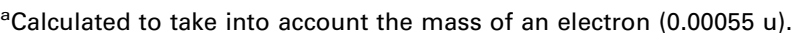

\section{Determination of Exact Mass}

The structures for the distonic radical cation and cyclopropene cationic species are further supported by the determination of the exact mass for these fragments (Table 2). These values were determined in triplicate and were $\leq 0.5 \mathrm{mmu}$ from the calculated mass taking into account the mass of an electron [35]. Complete details for the determination of the exact mass of a precursor or product ion can be found in references [36, 37].

\section{Conclusion}

Alkenamides that are doubly allylic were shown to fragment in a characteristic way to yield a distonic radical cation by homolytic cleavage and a cyclopropene or cyclopentadiene cation by a charge induced mechanism. These mechanisms are supported by the analysis of deuterated analogs, exact mass measurements, and the analysis of homologs that were not doubly allylic. ERMS data showed the distonic radical cation underwent subsequent fragmentations to form an acyllium ion with subsequent loss of $\mathrm{CO}$ to form an alkene cation. Notable exceptions to the formation of the distonic radical cation and cyclopropene cation were the doubly allylic cyclopropyl and ethanol alkenamides. ERMS data showed the acyllium ions formed from these compounds, by cleavage of the amide bond, occurred at a lower energy than the formation of the acyllium ions in alkenamides that fragmented to form the characteristic ions.

The authors hope the data presented in this work will facilitate the identification of these and other alkenamides and contribute to the fundamental understanding of the behavior of alkenamides in the collision cell of a triple quadrupole mass spectrometer.

\section{Acknowledgments}

The authors gratefully acknowledge the work of Dr. Joseph Mulholland and Mr. Jerry Pappas of Thermo Electron Corporation for the exact mass data reported in this paper and to Mr. Richard
Weber (Thermo Electron Corporation) for reviewing the mechanism for formation of the cyclopropene cationic species.

\section{References}

1. Greger, H. Alkamides: Structural Relationships, Distribution and Biological Activity. Planta Medica 1984, 50, 366375 .

2. Comparative Phytochemistry of the Alkamides. In Chemistry and Biology of Naturally-Occurring Acetylenes and Related Compounds (NOARC); Iam, J.; Breteler, H.; Arnason, T.; Hansen, L., Eds.; Elsevier: Amsterdam, The Netherlands, 1988; pp 159178.

3. Bryant, B. P.; Mezine, I. Alkamides that Produce Tingling Parethesia Activate Tactile and Thermal Trigeminal Neurons. Brain Res. 1999, 842, 452-460.

4. Nakatani, N.; Nagashima, M. Pungent Alkamides from Spilanthes acmella L. var. oleracea Clark. Biosci. Biotech. Biochem. 1992, $56,759-762$.

5. Adesina, S. K.; Akinwusi, D. D. New Constituents of Zanthoxylum tessmanii (Engl.) Ayafor Root. J. High Res. Chromatogr./ Chromatogr. Commun. 1986, 9, 412-414.

6. Adesina, S. K. Further New Constituents of Zanthoxylum leprieurii. Fitoterapia 1987, 58, 123-126.

7. Adesina, S. K. Further Novel Constituents of Zanthoxylum zanthoxyloides Root and Pericarp. J. Nat. Prod. 1986, 49, 715716 .

8. Bryant, B. P. Trigeminal Sensory Stimuli and Animal Repellants from Plants. Int. Pat. Appl. 1999, WO 9921425 A1 19980923.

9. Nagashima, M.; Nakatani, N. LC-MS Analysis and Structure Determination of Pungent Alkamides from Spilanthes acmella L. Flowers. Lebensm. Wiss. Technol.1992, 25, 417-421.

10. He, X.-G.; Lin, L.-Z.; Bernart, M. W.; Lian, L.-Z. Analysis of Alkamides in Roots and Achenes of Echinacea purpurea by Liquid-Chromatography Electrospray Mass Spectrometry. J. Chromatogr. A 1998, 815, 205-211.

11. Wysocki, V. H.; Ross, M. M.; Horning, S. R.; Cooks, R. G. Remote-Site (Charge-Remote) Fragmentation. Rapid Commun. Mass Spectrom. 1988, 2, 214-217.

12. Adams, J. Charge-Remote Fragmentations: Analytical Applications and Fundamental Studies. Mass Spectrom. Rev. 1990, 9, 141-186.

13. Antoine, M.; Adams, J. Implication of the Charge Site in "Charge-Remote" Fragmentations. J. Am. Soc. Mass Spectrom. 1992, 3, 776-778.

14. Adams, J.; Songer, M. J. Charge-Remote Fragmentations for Structural Determination of Lipids. Trends Anal. Chem. 1993, $12,28-35$. 
15. Cheng, C.; Pittenauer, E.; Gross, M. L. Charge-Remote Fragmentations are Energy-Dependent Processes. J. Am. Soc. Mass Spectrom. 1998, 9, 840-844.

16. Cheng, C.; Gross, M. L. Applications and Mechanisms of Charge-Remote Fragmentation. Mass Spectrom. Rev. 2000, 19, 398-420.

17. Seto, C.; Grossert, J. S.; Waddell, D. S.; Curtis, J. M.; Boyd, R. K. Effects of Ionization Mode on Charge-Site-Remote and Related Fragmentation Reactions of Long-Chain Quaternary Ammonium Ions. J. Am. Soc. Mass Spectrom. 2001, 12, 571-579.

18. Denekamp, C.; Tenetov, E.; Horev, Y. Homolytic Cleavages in Pyridinium Ions, an Excited State Process. J. Am. Soc. Mass Spectrom. 2003, 14, 790-801.

19. Contado, M. J.; Adams, J.; Jensen, N. J.; Gross, M. L. A Charge-Remote Allylic Cleavage Reaction: Mechanistic Possibilities. J. Am. Soc. Mass Spectrom. 1991, 2, 180-183.

20. Angle- and Energy-Resolved Fragmentation Spectra from Tandem Mass Spectrometry. In Tandem Mass Spectrometry; McLafferty, F. W., Ed.; John Wiley and Sons: New York, 1983; pp 303-320.

21. Harrison, A. G. Energy-Resolved Mass Spectrometry: A Comparison of Quadrupole Cell and Cone-Voltage CollisionInduced Dissociation. Rapid Commun. Mass Spectrom. 1999, 13, 1663-1667.

22. Harrison, A. G. Fragmentation Reactions of Alkylphenylammonium Ions. I. Mass Spectrom. 1999, 34, 1253-1273.

23. Lemaire, D.; Serani, L.; Laprevote, O.; Ovcharenko, V.; Pihlaja, K.; Stajer, G. Energy-Resolved Electrospray Mass Spectrometry of Diexo-Norbornane and Norbornene Derivatives Containing a Fused, Phenyl-Substituted, 1,3-Oxazine Ring: Competitive Retro-Diels-Alder Fragmentation Processes Eur. Mass Spectrom. 1999, 5, 253-257.

24. Wensing, M. W.; Snyder, A. P.; Harden, C. S. Energy Resolved Mass Spectrometry of Diethyl Alkyl Phosphonates with an Atmospheric Pressure Ionization Tandem Mass Spectrometer. J. Mass Spectrom. 1995, 30, 1539-1545.

25. Wensing, M. W.; Snyder, A. P.; Harden, C. S. Energy Resolved Mass Spectrometry of Dialkyl Methylphosphonates with an Atmospheric Pressure Ionization Tandem Mass Spectrometer. Rapid Commun. Mass Spectrom. 1996, 10, 1259-1265.

26. Dyson, P. J.; Johnson, B. F. G.; McIndoe, J. S.; Langridge-Smith, P. R. R. Energy-Dependent Electrospray Mass Spectrometry: Applications in Transition Metal Carbonyl Chemistry. Rapid Commun. Mass Spectrom. 2000, 14, 311-313.
27. Fetterolf, D. D.; Yost, R. A. Energy-Resolved Collisionnduced Dissociation in Tandem Mass Spectrometry. Int. J. Mass Spectrom. Ion Phys. 1982, 44, 37-50.

28. Begala, M.; Delogu, G.; Maccioni, E.; Podda, G.; Tocco, G.; Quezada, E.; Uriarte, E.; Fedrigo, M. A.; Favretto, D.; Traldi, P. Electrospray Ionization Iandem Mass Spectrometry in the Characterization of Isomeric Benzofurocoumarins. Rapid Commun. Mass Spectrom. 2001, 15, 1000-1010.

29. Kenttamaa, H. I.; Cooks, R. G. Tautomer Characterization by Energy Resolved Mass Spectrometry. Dimethyl Phosphite and Dimethyl Phosphonate Ions. J. Am. Chem Soc. 1985, 107, 1881-1886.

30. Weinmann, W.; Stoertzel, M.; Vogt, S.; Wendt, J. Tune Compounds for Electrospray Ionization/In-Source CollisionInduced Dissociation with Mass Spectral Library Searching. J. Chromatorg. A 2001, 926, 199-209.

31. Weinmann, W.; Stoertzel, M.; Vogt, S.; Svoboda, M.; Schreiber A. Tuning Compounds for Electrospray Ionization/In-Source Collision-Induced Dissociation and Mass Spectra Library Searching. J. Mass Spectrom. 2001, 36, 1013-1023.

32. Qin, X.-Z. Atmospheric Pressure Ionization Tandem Mass Spectra of Protonated Timolol. J. Mass Spectrom. 1999, 34, 51-59.

33. Hsu, F.-F.; Turk, J. Charge-Remote and Charge-Driven Fragmentation Processes in Diacyl Glycerophosphoethanolamine Upon Low-Energy Collisional Activation: A Mechanistic Proposal. J. Am. Soc. Mass Spectrom. 2000, 11, 892-899.

34. Wang, H.; Wu, Y.; Zhao, Z. Fragmentation Study of Simvastatin and Lovastatin Using Electrospray Ionization Tandem Mass Spectrometry. J. Mass Spectrom. 2001, 36, 58-70.

35. Bristow, A. W. T.; Webb, K. S. Intercomparison Study of Accurate Mass Measurement of Small Molecules in Mass Spectrometry. J. Am. Soc. Mass Spectrom. 2003, 14, 10861098.

36. Paul, G.; Winnik, W.; Hughes, N.; Schweingruber, H.; Heller, R.; Schoen, A. Accurate Mass Measurement at Enhanced Mass-Resolution on a Triple Quadrupole Mass-Spectrometer for the Identification of a Reaction Impurity and CollisionallyInduced Fragment Ions of Cabergoline. Rapid Commun. Mass Spectrom. 2003, 17, 561-568.

37. Hughes, N.; Winnik, W.; Dunyach, J.-J.; Amad, M.; Splendore, M.; Paul, G. High-Sensitivity Quantitation of Cabergoline and Pergolide Using a Triple-Quadrupole Mass Spectrometer with Enhanced Mass-Resolution Capabilities. J. Mass Spectrom. 2003, 38, 743-751. 